\title{
Reconhecimento fotográfico e presunção de inocência
}

\author{
Photographic Eyewitness Identification and \\ the Presumption of Innocence
}

\section{Janaina Matida ${ }^{1}$}

Universidade Alberto Hurtado, Santigo, Chile

janainamatida@gmail.com

http://lattes.cnpq.br/0726953790052272

https://orcid.org/0000-0003-0963-1848

\section{William Weber Cecconello ${ }^{2}$}

Pontifícia Universidade Católica do Rio Grande do Sul, Porto Alegre/RS, Brasil william.cecconello@gmail.com http://lattes.cnpq.br/1782277694993596

https://orcid.org/0000-0001-6890-2076

Resumo: O reconhecimento de pessoas é uma prova importante para o processo penal, entretanto, inocentes podem ser reconhecidos por crimes que não cometeram. Procedimentos adotados para o reconhecimento podem aumentar a probabilidade de um falso reconhecimento, como a apresentação de um único suspeito (show-up), ou múltiplos suspeitos ao mesmo tempo (álbum de suspeitos). Neste contexto de manifestas irregularidades, o reconhecimento por método fotográfico é tido como pouco confiável no Brasil, sendo preferível o reconhecimento presencial. Neste artigo, a partir do diálogo entre a epistemologia jurídica e da psicologia do testemunho, considerando pesquisas e experimentos, refletimos sobre as vantagens e possibilidades da realização

1 Professora da Universidade Alberto Hurtado (Chile). Doutora em Direito pela Universitat de Girona (Espanha). Associada do Instituto de Defesa do Direito de Defesa (IDDD), consultora do projeto Prova sob Suspeita (IDDD).

2 Professor de Psicologia (IMED). Mestre em Psicologia pela PUCRS (2017). Atualmente é doutorando em Psicologia com ênfase em Cognição Humana pela PUCRS, com período sanduíche na University of Portsmouth. 
de reconhecimento por método fotográfico como forma facilitar um procedimento de alinhamento justo. São apresentados dados empíricos da psicologia experimental que confirmam resultados do método fotográfico para reconhecimento e, ao final, com base neles, são apresentados argumentos para a sua adoção rumo à construção de um processo penal brasileiro de contornos democráticos, que assegure alcance efetivo à presunção de inocência.

Palavras-chave: psicologia do testemunho; epistemologia jurídica; prova penal; reconhecimento fotográfico; presunção de inocência.

AвSTRACT: Eyewitness identification is an important criminal evidence for the justice system, however, innocent people can be identified for crimes that they did not commit. Procedures adopted for recognition may increase the likelihood of false identification, such as the presentation of a single suspect (show-up), or multiple suspects at the same time (suspects album). In a context of patent irregularities, eyewitness identification through photographs are believed to be less reliable in Brazil, where the live identification is preferred. In this paper, from legal epistemology and psychology of testimony, we approach the advantages and possibilities of photo eyewitness identification as a method to enable a fair lineup procedure. Empirical data from experimental and cognitive psychology are presented that confirm the results of photographic method for eyewitness identification and, in the end, arguments are presented for the adoption towards the construction of a Brazilian democratic criminal code, which ensures effective reach to the presumption of innocence.

KEYwORDs: psychology of testimony; legal epistemology; criminal evidence; photographic eyewitness identification; presumption of innocence.

\section{INTRODUÇÃO}

Quando se trata da determinação dos fatos no contexto da justiça criminal, o reconhecimento de pessoas é prova a que se oferece protagonismo. Embora um conjunto probatório possa apresentar uma série de outros elementos, é usual que investigadores, acusadores e magistrados atribuam considerável relevância ao fato de um sujeito ter sido apontado pela vítima/testemunha como autor do delito. Mais ainda quando essa 
indicação vem acompanhada por um elevado grau de certeza ("Estou $100 \%$ convicto de que foi esta a pessoa que me assaltou"), ou quando se relata o fato com riqueza de detalhes. A sobrevaloração dessa combinação de elevada confiança e detalhes fartos, por sua vez, descansa na crença equivocada de que a memória humana funcionaria como uma máquina filmadora, capaz de armazenar de modo não problemático todos os fatos vividos por alguém (Loftus, 2005).

Segundo o senso comum, sem maiores dificuldades, a memória seria capaz de entregar o conteúdo dos fatos vividos a qualquer momento. No entanto, como amplamente já sinalizado pelos autores deste artigo e outros pesquisadores (Vieira, 2019; Machado; Moretzsohn; Burin, 2020) definitivamente esta não é uma boa descrição de como a memória humana funciona (Cecconello, Ávila \& Stein, 2019). O registro, o armazenamento e a recuperação de seu conteúdo enfrentam dificuldades não desprezíveis. Quanto mais tempo passa do momento em que o fato se deu, por exemplo, maior a probabilidade de descompasso entre o que aconteceu e o que será oportunamente relatado. A qualidade das informações gravadas na memória é degradável, flexível e maleável, não sendo correto esperar que somente sujeitos com problemas cognitivos possam oferecer relatos pouco precisos do que viveram ou testemunharam.

Em vista disso, é preciso considerar o risco das falsas memórias, que podem ser a recordação de informações que não ocorreram, ou o reconhecimento de um inocente como sendo erroneamente autor de um crime. A falsa memória não é uma mentira, não se confunde com a deliberada intenção de faltar com a verdade. Nas falsas memórias, por contaminação do registro, armazenamento ou na tentativa de se recuperar o fato ocorrido, falta correspondência entre o que aconteceu e o que é recordado (Stein, 2009). O fato ocorrido é $x$, mas a vítima/testemunha, por variáveis que atuam dificultando o registro, o armazenamento ou a recuperação, recorda $y$ e, por isso, relata $y$. A falsa memória acompanhada da sinceridade do relato provoca um erro honesto; um descompasso entre o relatado e o ocorrido que é, inobstante, bem intencionado. $\mathrm{Na}$ mentira, vale esclarecer, para continuar com o mesmo exemplo do fato $x$, a vítima/testemunha recorda $x$ e relata deliberadamente o fato $y$. $\mathrm{O}$ descompasso entre o relatado e o experenciado por ela não é bem intencionado, mas desonesto. 
É ilusório, portanto, esperar da memória um funcionamento regular infalível. Com isso, não estamos negando valor epistêmico à memória, mas destacando a importância de se distinguir a memória tal como ela é da memória que gostaríamos que fosse: a reconstrução dos fatos no processo penal será tanto mais confiável a medida em que mais nos acerquemos da primeira e nos distanciemos da segunda.

No que refere especificamente à prova de reconhecimento, a preservação do mito da "memória-máquina filmadora" significa aquiescer a falsos negativos e a falsos positivos, isto é, à absolvição de culpados e à condenação de inocentes. De outro lado, compreender as limitações constitutivas da memória humana torna necessária a tomada de uma série de providências no âmbito probatório - seja no que refere à produção, seja no que refere à valoração probatória, seja, finalmente, no que se refere à adoção de uma decisão sobre os fatos ${ }^{3}$. Entre essas providências, os autores deste trabalho entendem constar a consideração do reconhecimento na modalidade fotográfica como alternativa séria a ser discutida. A utilização de fotografias/imagens do suspeito não deve ser descartada tão rapidamente, sobretudo se se almeja reduzir o risco de se condenar inocentes injustamente (Cecconello; Stein, 2020; Matida, 2020). Essa afirmação pode parecer contraintuitiva para aqueles que estão cansados das notícias sobre casos em que o uso de fotografia veio acompanhado de manifestas ilegalidades. A desconfiança diante do uso de fotografias para o reconhecimento é perfeitamente justificada no atual estado de coisas de seletividade penal no qual nos encontramos.

No entanto, é pensando justamente em reverter esse cenário de esvaziamento de garantias dos investigados/acusados que nos dedicaremos a oferecer argumentos favoráveis ao reconhecimento fotográfico. Em

3 Em razão do limite de espaço, a relação entre standard probatório e provas dependentes da memória não será analisada. Mas é inegável que a constatação da falibilidade da memória traz importantes consequências para a resposta sobre se um standard probatório adequado ao processo penal pode ou não ser superado por uma hipótese fática seja única e exclusivamente uma prova dependente da memória, como a palavra de alguém ou o reconhecimento realizado por alguém. É entendimento de um dos autores deste artigo de que não é possível, por exemplo, superar o standard probatório elevado que o processo penal merece a partir de um reconhecimento de pessoa. Sobre o tema, ver Matida, 2019. 
definitivo, não é qualquer coisa que pode ser considerado reconhecimento fotográfico e aqui cuidaremos dos requisitos que, se presentes, fazem dele um modo de conferir contornos mais efetivos à presunção de inocência a que todos os cidadãos têm direito. A confiabilidade do resultado de um reconhecimento depende da realização de um alinhamento justo, no qual nenhum de seus componentes tenha destaque sobre os demais presentes. Tendo isso em consideração, como assegurar, para cada reconhecimento a ser realizado presencialmente nas unidades policiais a disponibilidade de uma pluralidade de pessoas semelhantes entre si? Esperar que estas condições sempre se dêem para a realização da modalidade presencial é, no mínimo, irreal (Matida, 2020, Matida; Nardelli, 2020).

Isso nos leva a ter de encarar de frente o reconhecimento fotográfico e investigá-lo com mais cautela. Ele pode ser uma alternativa viável às inafastáveis limitações práticas do reconhecimento presencial. Ademais, fotográfico ou presencial, a confiabilidade do reconhecimento depende da implementação de um alinhamento que seja justo. Estas observações iniciais tornam evidente, mas não custa explicitar, que a prática conhecida como "álbum de suspeitos" não será aqui defendida. Justo ao contrário: abordar seriamente a temática do reconhecimento fotográfico implica rechaçar de pronto práticas odiosas como o álbum de suspeitos e a exposição de imagens dos suspeitos displicentemente extraídas das redes sociais.

Dessa feita, a partir da epistemologia jurídica e da psicologia do testemunho, propomos o aprofundamento dos debates sobre o reconhecimento fotográfico. Da epistemologia jurídica deve-se a preocupação com a revisão de regras e práticas probatórias capazes de dotar a determinação dos fatos de sistemas jurídicos concretos de maior porosidade à verdade dos fatos ${ }^{4}$. Essa preocupação com a verdade é precisamente o que justifica

4 Sobre esta acepção de "epistemologia jurídica”, ver Matida; Herdy (2016), p. 209: “(...) nesta segunda acepção, a Epistemologia Jurídica reflete preocupações com o conhecimento dos fatos, e não do direito. Não se trata de problematizar a produção de conhecimento jurídico. A questão que interessa é a justificação das proposições sobre os fatos que integram o raciocínio do julgador no momento em que se lhe exige uma decisão sobre quem merece a tutela jurisdicional no caso individual. Essa forma de entender a Epistemologia Jurídica requer um retorno à Epistemologia Tradicional enquanto disciplina filosófica. Enquanto os epistemólogos em geral ocupam-se da justificação 
a aproximação com a psicologia do testemunho 5 . O franco diálogo com a psicologia do testemunho é mais do que adequado à redução de erros judiciários, a medida que profissionais daquela área é que vêm se dedicando a realizar pesquisas e experimentos sobre como a memória humana efetivamente funciona e, assim, podemos conhecer suas potencialidades e suas limitações. O adequado tratamento da prova de reconhecimento depende, portanto, da soma de resultados que a epistemologia jurídica, a psicologia do testemunho e uma alta dogmática processual penal é capaz de produzir ${ }^{6}$.

Dito isso, nosso trajeto argumentativo contemplará, no item 2, a apresentação de problemas associados ao reconhecimento fotográfico no Brasil, os quais, à continuação, serão contrastados com procedimentos baseados em evidência, desenvolvidos a partir de experimentos e pesquisa científica. A exigência de um alinhamento justo, que não incremente a sugestividade de um procedimento que inerentemente já é sugestivo, como é o caso do reconhecimento, será tema do item 3. Os argumentos trazidos neste item servirão a demonstrar que o alinhamento do suspeito com pessoas sabidamente inocentes é condição necessária para que se

de uma proposição fática p, os epistemólogos jurídicos ocupam-se da justificação de uma proposição p quando esta é uma informação relevante para a decisão judicial. Concretamente, a Epistemologia Jurídica é um tipo de Epistemologia Aplicada - um estudo sobre o sistema jurídico como uma prática institucional que tem como um de seus objetivos a busca pela verdade". Um dos autores deste artigo considera-se integrante desta específica maneira de abordar o problema da determinação dos fatos no ambiente do processo. Aproveitamos para listar Prado (2014, 2019), Badaró (2019), Herdy (2016), Nardelli (2019), Ramos (2018), Badaró (2018) e Vieira (2020) como outros expoentes da epistemologia jurídica no cenário nacional.

5 Sobre o necessário diálogo entre a adequada determinação dos fatos no ambiente dos tribunais e a psicologia do testemunho, ver Matida, Nardelli e Herdy (2020), Badaró (2019) e Ramos (2018).

6 A necessidade de diálogo entre as diversas áreas de conhecimento também é reconhecida por Giacomolli; di Gesu (2008), ao fazerem referência à "falência do monólogo científico". Além de Nereu Giacomolli e Cristina di Gesu, Aury Lopes Jr. (2020), Alexandre Morais da Rosa (2020), Gustavo Badaró (2016), e Mariângela Tomé Lopes (2011) são exemplos de dogmáticos processualistas penais preocupados com a construção de pontes com outras áreas de conhecimento como estratégia de redução dos riscos de condenação de inocentes. 
possa conferir qualquer valor, reduzido que seja, ao resultado do feito. Finalmente, no item 4 apresentaremos argumentos favoráveis ao reconhecimento fotográfico. Dito aqui, muito sucintamente, é a ausência de um alinhamento justo, e não o emprego da fotografia em si o que deve nos causar justificada preocupação. O reconhecimento fotográfico despontará, neste último item, como uma alternativa procedimental não apenas compatível, mas necessária ao sistema de justiça criminal de corte garantista. Nosso compromisso com a redução de erros judiciários, com o risco de se condenar inocentes, é o que precisamente justifica a necessidade de se conceder um olhar mais depurado ao reconhecimento fotográfico.

\section{Problemas do reconhecimento de pessoas no Brasil}

No Brasil, o reconhecimento fotográfico é comumente referido como um procedimento informal que antecede o reconhecimento presencial. Ou seja, caso a vítima ou testemunha reconheça o suspeito por foto realiza-se um reconhecimento presencial (Stein; Ávila, 2015). Ângelo Gustavo $^{7}$ e Thiago Braga Brum ${ }^{8}$ tiveram seus rostos conhecidos por imagens extraídas de redes sociais, sem que se realizasse qualquer controle quanto à qualidade e características das imagens. Já Bárbara Quirino ${ }^{9} \mathrm{e}$ Tiago Vianna Gomes ${ }^{10}$ tiveram seus rostos reconhecidos por fotografia enviada à vítima por whatsapp e posteriormente reexibida por álbum de suspeitos. Nem a diferença de estatura de $15 \mathrm{~cm}$ entre Tiago e a descrição que a vítima ofereceu do real perpetrador da conduta foi bastante para que fosse descartado como suspeito; nem a localização em outra cidade

7 Sobre o caso de Ângelo Gustavo: https://www1.folha.uol.com.br/cotidiano/2020/11/familia-tenta-provar-inocencia-de-jovem-condenado-apos-ser-reconhecido-por-foto-de-rede-social.shtml. Acesso em nov. de 2020.

8 Sobre o caso de Thiago Braga Brum: https://mi.tv/br/programas/em-nome-da-justica-s01e11-tiago-rafael. Acesso em nov. de 2020.

9 Sobre o caso de Bárbara Quirino: https://ponte.org/barbara-querino-a-babiy-como-a-justica-condenou-uma-jovem-negra-sem-provas/. Acesso em nov. de 2020 .

10 Sobre o caso de Tiago Vianna Gomes: https://iddd.org.br/jovem-negro-condenado-apos-falso-reconhecimento-tera-caso-julgado-pelo-stj/ Acesso em nov. de 2020 . 
de Bárbara na data do fato, corroborada por fotos e testemunhas de defesa, foi suficiente para derrotar seu reconhecimento pela vítima, que se aferrou ao "cabelo parecido" de Bárbara e a real culpada. E embora Bárbara e Tiago tenham sido absolvidos em decisões que reconheceram a fragilidade probatória em que suas condenações injustificadamente se apoiaram, o mesmo não se pode dizer de Ângelo Gustavo e Thiago Braga Brum, os quais ainda aguardam julgamento - aquele preso, à espera de revisão criminal; este em prisão domiciliar, à espera do recurso especial. Casos como esses colocam em destaque o pouco - o nada, a bem dizer - que é tido como suficiente para condenações criminais no Brasil (Matida; Nardelli, 2020).

Esse "nada", no que refere ao reconhecimento, expressa-se na admissão do desregrado uso de imagens que, por seu turno, é combinado ao reconhecimento presencial que ocorre primeiro na delegacia, depois em audiência sob os cuidados do magistrado. Significa dizer que, no Brasil, vítimas e testemunhas são submetidas a reconhecer os suspeitos diversas vezes: sobrepõe-se a exibição de fotos/imagens dos suspeitos em múltiplos momentos (whatsapp com a vítima a caminho da delegacia e álbum de suspeitos já na delegacia, por exemplo) à exposição presencial dos rostos de suspeitos em unidade policial e depois em juízo. Tal repetição em juízo seria devida à proibição de se condenar com base em elementos informativos (produzidos exclusivamente em etapa investigatória). Essa prática serviria a sanar eventuais irregularidades praticadas na fase preliminar, de modo que a repetição do ato seria uma espécie de antídoto a vícios anteriores. O que dizer sobre as nossas práticas?

Nada mais contraepistêmico porquanto contrário às descobertas feitas pela psicologia do testemunho. Do ponto de vista cognitivo, o reconhecimento é um procedimento irrepetível. Quando um crime é praticado, a vítima/testemunha armazena em sua memória uma representação mental do autor e, posteriormente, é solicitada a prestar declarações bem como realizar o reconhecimento. A descrição dos fatos oferecida pelos envolvidos e a identificação da autoria dos responsáveis por comportamentos juridicamente proibidos são recursos aos quais confere-se destacada importância, de sorte que não se trata de qualquer exagero afirmar que a determinação dos fatos na justiça criminal depende, em grande medida, da memória humana. Contudo, embora 
testemunho ${ }^{11}$ e reconhecimento sejam espécies do gênero provas dependentes da memória, não se pode perder de vista que seus processos cognitivos são diferentes entre si. A repetibilidade do procedimento de sua produção representa uma dessas diferenças: quando técnicas de entrevistas adequadas são aplicadas, é possível que as informações recuperadas sejam relatadas pela vítima/testemunha repetidas vezes, sem que, necessariamente, haja prejuízo quanto à fidedignidade de seu conteúdo. O mesmo não se pode afirmar do reconhecimento, dado tratar-se de procedimento inerentemente sugestivo.

Nele, a vítima/testemunha é apresentada a um ou mais rostos para que se decida se um dos rostos corresponde ao rosto visto quando o delito era cometido. Ou seja: o testemunho parte da memória da vítima/ testemunha em sentido ao mundo externo; por outro lado, o reconhecimento parte do mundo externo em sentido à memória (Cecconello; Ávila; Stein, 2018). Assim, uma vez que um rosto é reconhecido como sendo do autor do delito, a memória original para aquele rosto é alterada e reconhecimentos subsequentes estarão, desde logo, comprometidos. A função da memória humana é aprender, não recordar de delitos; sendo assim, ao reconhecer um rosto, o cérebro "aprende" que este rosto - seja de um inocente, seja do culpado - corresponde ao próprio autor do crime (Cecconello; Stein, 2020).

Achados empíricos reforçam a irrepetibilidade do reconhecimento. Steblay e Dysart (2016) realizaram experimento em que verificaram que quando o reconhecimento inicial era falso (seleção de um inocente no lugar do culpado), os reconhecimentos subsequentes apresentavam a tendência de reconhecer o mesmo suspeito inocente, mesmo quando este era apresentado ao lado do real autor do fato. Esforços como estes feitos pela psicologia cognitiva demonstram que o resultado de um reconhecimento atual está comprometido pelos reconhecimentos que lhe precederam. Isso joga por terra o valor epistêmico do reconhecimento

11 O termo "testemunho" é empregado aqui em um sentido mais amplo. Tal como na psicologia do testemunho se estabelece, trata-se de testemunho o relato oferecido por qualquer pessoa que tenha vivido ou presenciado um fato/ evento. Logo, os relatos trazidos pela vítima, pelo ofensor, por testemunhas são considerados “testemunhos”. Há, portanto, diferença entre esse significado mais amplo e o significado técnico-jurídico do termo. 
feito em juízo, pois é incapaz de anular efeitos deletérios de reconhecimentos incorreta e anteriormente realizados (Steblay; Dysart, 2016, Wells et al, 2020).

No Brasil, o reconhecimento a partir de fotografia é realizado de dois modos: o show-up e o álbum de suspeitos. No show-up fotográfico, apresenta-se uma foto do suspeito à vítima/testemunha, que é solicitada a dizer se é ou não o autor do delito (Stein; Ávila, 2015). Seja presencial ou fotográfico, o problema do show-up reside na falta de alternativa para que a vítima/testemunha possa comparar rostos. Em um show up a vítima pode chegar a reconhecer o suspeito como autor do crime simplesmente em razão de apresentar características semelhantes ao autor (o mesmo corte de cabelo, por exemplo). O show-up é um procedimento notoriamente sugestivo e, por representar grande risco a falsos reconhecimentos, é constantemente desaconselhado por pesquisadores como procedimento de reconhecimento (Cecconello; Stein, 2020; Clark, 2012; Wells et. al., 2020;).

Além do show-up, o álbum de suspeitos também é recorrentemente utilizado nas investigações criminais. Trata-se de peça fundamental da rotina policial. Por meio dele, uma pluralidade de suspeitos é apresentada ao mesmo tempo. Se uma vítima de roubo procura ajuda em uma delegacia, a ela será exibido um álbum com inúmeros indivíduos previamente selecionados pelas autoridades policiais. Não há clareza quanto ao que serve de razão para que alguém passe a compor um álbum de suspeitos.

O caso de Luiz Carlos da Costa Justino, violoncelista da Orquestra da Grota, ilustra a falta de transparência quanto ao que serve de critério para a inclusão da fotografia de alguém no álbum de suspeitos. Justino foi abordado depois de uma apresentação na região das Barcas, em Niterói (Rio de Janeiro). É possível perceber, em realidade, a sucessão de arbitrariedades presentes no caso, já que tampouco se pode compreender o que, exatamente, Justino fazia, que pudesse ter sido interpretado como "atitude suspeita". Abordado após o término de sua apresentação musical, Justino foi conduzido à delegacia em razão de mandado de prisão preventiva expedido por um roubo de celular e dinheiro ocorrido em 2017. Sua participação em ação realizada por quatro pessoas foi determinada pela seleção de sua foto num álbum de suspeitos. Mas como a sua foto 
foi parar ali? Essa foi uma das perplexidades enfrentadas pelo magistrado André Nicolitt ao deferir habeas corpus impetrado a favor de Justino.

Precisamente sobre o caso, causa perplexidade como a foto de alguém primário, de bons antecedentes, sem qualquer passagem policial vai integrar álbuns de fotografias em sede policial como suspeito.

(...) Da análise dos termos de declarações (0000029) e do relatório do inquérito (0000044) às fls. 46, percebe-se que no mesmo dia a vítima registrou o fato e já the foi apresentado um álbum de suspeitos. Se este álbum não foi constituído de uma prévia investigação sobre os fatos, o que levou a supor que certos indivíduos possam ter participado do crime, este álbum de suspeitos só pode significar na acepção do Dicionário Aurélio, um álbum de pessoas que "inspiram desconfiança. (Decisão de revogação de prisão preventiva de André Nicolitt, TJ-RJ, Comarca de São Gonçalo, Proc. n. 0021082-75.2020.8.19.0004, p. 5).

O caso de Tiago Vianna Gomes também merece ser recordado ao se tratar da prática de álbum de suspeitos. Em recente decisão do HC $619.327 / \mathrm{RJ}^{12}$, o Superior Tribunal de Justiça, sob a relatoria do Min. Sebastião Reis Junior, pôs um fim à injusta condenação de Tiago, condenado por roubo a mão armada de uma motocicleta, ocorrido em 2017. Tampouco no caso de Tiago pode-se indicar a partir de que momento sua fotografia passou a integrar um dos álbuns de suspeitos então exibido à vítima. Fato é que, como não há controle dos critérios para ingresso, nem do momento a partir do qual a autoridade policial tem a obrigação de exclusão, apesar de ser absolvido por um processo de receptação (anterior ao processo de roubo), a foto de Tiago continuou a ser reiteradamente exibida a vítimas aleatórias, a despeito de que houvesse discrepância entre as características do culpado descritas pelas vítimas e as de Tiago. Era uma questão de tempo para que o procedimento do álbum, sugestivo por excelência, gerasse seus "frutos". Tiago foi reconhecido nada menos que oito vezes.

12 O caso contou com a participação do Instituto de Defesa do Direito de Defesa (IDDD) e do Innocence Project Brasil na condição de amicus curiae. Para mais informações sobre o caso, acesso ao inteiro teor do HC 619.327/RJ, do amicus curiae do IDDD, ver: https://iddd.org.br/jovem-negro-condenado-apos-falso-reconhecimento-tera-caso-julgado-pelo-stj/ 
Que Tiago tenha sido reconhecido oito vezes diz mais sobre o risco de falsos reconhecimentos que ronda a população preta e pobre brasileira e muito menos sobre a confiabilidade da informação gerada. Sintoma disso é que, mesmo depois da absolvição por um primeiro processo de receptação, a fotografia de Tiago continuou a ser reiteradamente oferecida a vítimas que, com a memória acometida por decurso de tempo, estresse, efeito da raça diferente, entre outras variáveis, acabaram por apontar Tiago como autor dos delitos. Vale ressaltar que as vítimas que reconheceram Tiago chegaram a descrever o autor do fato com base em características físicas destoantes das de Tiago" (Matida; Nardelli, 2020).

Em síntese, seria ilusório esperar diferente, porque em circunstâncias de patente arbitrariedade, ser novamente reconhecido é questão de sorte/azar, uma "verdadeira roleta russa" (Matida; Nardelli, 2020). É de se notar que o emprego dos álbuns de foto suspeitos é terreno franqueado às arbitrariedades, tanto porque inexistem critérios para a inclusão/ exclusão das imagens, quanto porque há verdadeira lacuna quanto aos protocolos que devem ser seguidos para que a maneira de se conduzir o ato não represente, em si mesma, um fator de contaminação da memória da vítima/testemunha. A acurácia do resultado depende da adoção de critérios e protocolos para o uso de fotografias.

Importa ainda destacar que a prática do álbum combina-se à "visão de túnel".

Visão de túnel é uma tendência humana natural que tem efeitos particularmente perniciosos no sistema de justiça criminal. Por visão de túnel, referimo-nos a um 'compendio de heurísticas comuns e falácias lógicas' as quais estamos todos suscetíveis, que conduzem os atores do sistema de justiça criminal a focarem no suspeito, selecionarem e filtrarem as provas que construirão o caso para a condenação, ao mesmo tempo que ignoram ou suprimem as provas que apontam para longe da culpa. (Findley; Scott, 2006)

Ou seja: não bastasse o simples emprego de tão questionável procedimento, a ele sobrepõe-se a visão de túnel. O álbum é comumente utilizado como ponto de partida da investigação criminal. Investigadores partem da suposição de que a imagem do autor está catalogada e poderá 
ser verificada a partir de uma exibição sem maiores cuidados, o que acaba por desviar a atenção que outros elementos informativos também deveriam ganhar. São os estereótipos raciais e sociais que terminam por sedimentar a crença de que a apresentação do álbum com tantos suspeitos já será suficiente para solucionar o caso em questão. A robustez do conjunto informativo é comprometida porque se atribui excessivo valor ao resultado de um procedimento que em nada contribui à aproximação à verdade dos fatos.

Tanto é assim que os pesquisadores da psicologia do testemunho têm justamente recomendado que o reconhecimento não seja o primeiro procedimento da investigação (Wells et al., 2020). O reconhecimento deve ser consequência de outras informações colhidas no decorrer da investigação, não seu ponto de partida. Assim, uma vez outros elementos informativos apontem para um suspeito, aí sim, o reconhecimento deverá ser realizado; vale ressaltar, sempre de acordo com a exigência do alinhamento justo.

\section{Alinhamento justo, instruções e ausência de feedback's}

Em primeiro lugar, "alinhamento" opõe-se a "show-up". Alinhamento é procedimento por meio do qual se exibe o suspeito à vítima/ testemunha na companhia de outras pessoas, evitando-se com isso, a efeito radicalmente sugestivo de se mostrar uma única pessoa (show-up). Como vimos anteriormente, há inclusive experimentos que dão conta de demonstrar que a apresentação de uma única pessoa fará que seja ela a tendencialmente selecionada nos próximos reconhecimentos, pouco importando se ela é ou não a culpada. A técnica de se alinhar uma pluralidade de pessoas pretende eliminar essa primeira e radical sugestionabilidade da memória da vítima/testemunha, evitando, com isso, a implantação em sua memória do rosto daquela pessoa que lhe fora exibida individualmente. Para usar os termos adequados e anteriormente mencionados, quer-se evitar a formação de uma falsa memória e a produção de um erro honesto a partir dela.

O alinhamento de uma pluralidade de pessoas é técnica válida para evitar falsas memórias e erros honestos. Mas não basta que haja simples alinhamento. É preciso que ele seja justo. Em um alinhamento justo, o 
suspeito é apresentado em meio a pessoas não suspeitas ${ }^{13}$ (geralmente, totalizando seis). Para que o alinhamento seja eficaz, os não suspeitos devem ser sabidamente inocentes e, assim como o suspeito, devem atender à descrição da vítima/testemunha, de modo que o suspeito não se destaque entre os demais (Wells; Olson, 2003). Primeiro falaremos da exigência de ausência de destaque e, em seguida, da condição de que os outros integrantes do alinhamento sejam não suspeitos, isto é, sabidamente inocentes.

Em primeiro lugar, sempre que haja destaque não se estará a promover um alinhamento justo, mas tão-somente um alinhamento formal que não protege inocentes do risco de serem falsamente apontados. Utilizando o caso de Bárbara Quirino como exemplo, se em lugar de ter sido exibida por show-up através fotografia enviada pelo whatsapp à vítima, Bárbara tivesse sido exibida numa fila de pessoas brancas ao seu lado, ou de pessoas que não tinham o mesmo cabelo volumoso que foi descrito como característica da culpada pela vítima e que era preenchida por Bárbara, também não seria possível afirmar, nestas hipóteses, que seu alinhamento fora justo. $\mathrm{O}$ alinhamento em que somente uma pessoa preenche as características descritas pela vítima/testemunha como sendo as características do culpado/da culpada não é um alinhamento justo porque a própria composição do alinhamento cria a tendência de que uma pessoa inocente seja apontada em razão da simples coincidência neste caso, triste coincidência - de que ela seja a única a ostentar um traço ou característica notada pela vítima/testemunha como sendo uma característica culpado/da culpada. Além disso, a ausência de destaque permite que a vítima/testemunha compare entre diferentes atributos dos rostos, sua decisão não será baseada em característica isolada senão que em múltiplas (Wixted et al, 2018).

Em resumidas linhas, ter cabelo volumoso, tatuagem, ser de determinada raça ou etnia, usar pearcing, não pode servir a, por si só, transformar pessoas em suspeitas de delitos. O efeito perverso de que a justiça criminal promova meras semelhanças com o culpado/a culpada a fatores dignos de suspeita é contribuir, no limite, à uma lógica que

13 Usaremos como sinônimos os termos "pessoas não suspeitas", "fillers" e "dublês". 
criminaliza raça, etnia, manifestações culturais. O cabelo volumoso de Bárbara, que expressa empoderamento do povo preto, nunca poderia ter sido suficiente à sua seleção como suspeita. Se se convalidam reconhecimentos como esse, ao fim e ao cabo, a mensagem que o sistema de justiça criminal estaria a transmitir à sociedade é de que basta pertencer a um grupo anteriormente categorizado como suspeito a partir de generalizações espúrias e discriminatórias ("negros de periferia"), pouco importando o indivíduo. Estados democráticos são incompatíveis com estas práticas.

No que refere à condição de não suspeitos das pessoas que são exibidas em conjunto com o suspeito, isso se deve à redução dos riscos de falsos reconhecimentos. Daí que, se se utiliza a técnica do show-up, sempre que o suspeito fosse um inocente estar-se-ia a contribuir para a sua injusta seleção como culpado. Quando se alinha o suspeito com pessoas sabidamente inocentes a probabilidade de um falso reconhecimento é distribuída entre as probabilidades de a vítima escolher algum não suspeito (Cecconello; Fitzgerald; Stein, no prelo; Wells; Smalarz; Smith, 2015). O reconhecimento de alguém sabidamente inocente (que são tecnicamente chamados de fillers) é resultado que não prejudica a investigação pois não se corre o risco de que ela seja ajustada a uma direção equivocada. O uso de fillers, que em realidade representam hipóteses fáticas as quais os investigadores sabem serem falsas, evita o cenário de erros judiciários reproduzidos a partir do álbum de suspeitos, por exemplo. No álbum, todo e qualquer sujeito é tido como um potencial suspeito; todo e qualquer apontamento tende a abrir uma linha investigativa que, aliada à visão de túnel há pouco descrita, servirá a cravar um erro judiciário. Por outro lado, a seleção do suspeito em procedimento que lhe apresentou na companhia de pessoas sabidamente inocentes e com ele semelhantes produz uma informação que deverá ser considerada pelo investigador cuidadoso.

Ainda sobre alinhamentos justos é sumamente importante que sejam utilizadas instruções adequadas às vítimas e testemunhas. Vítimas e testemunhas tendem a acreditar que caso não reconheçam um rosto estarão prejudicando o trabalho policial, por essa razão, é importante informar que o autor do delito pode estar ou não entre os rostos e que não reconhecer alguém é, sim, uma resposta possível (Steblay, 2013). 
Também é importante evitar qualquer feedback confirmatório, como quando o investigador diz à vítima/testemunha que ela apontou a pessoa que a polícia tinha em mente. Feedbacks como esse têm o efeito de inflar o grau de confiança que a vítima originalmente tinha no resultado, de modo que, a partir da confirmação oferecida pelo investigador, ela passa a ter um grau de confiança superior ao que originalmente tinha após ter efetuado o apontamento (Steblay; Wells; Douglass, 2014). Será esse grau de confiança inflado que a vítima/testemunha relatará quando perguntada sobre ele; como sabemos, ele poderá contribuir à injusta condenação de um inocente. Elevados graus de confiança não são, por si só, conclusivos sobre o conteúdo verdadeiro da memória. Sobre o perigo de se supervalorar um grau de confiança elevado, vejamos o caso de Janet Burke $^{14}$. Vítima de estupro no fim da década de 80, Janet apontou Thomas Haynesworth como seu algoz, relatando ter $100 \%$ de certeza quanto à autoria. Nas palavras de Janet, referindo-se ao momento em que esteve na presença do acusado, em audiência:

Eles (os policiais) o trouxeram. Assim que o vi comecei a me descontrolar. Parecia que eu estava revivendo a experiência de novo na frente de cem pessoas. Me lembro de ter apontado para o Thomas e ter dito 'tenho $100 \%$ de certeza de que é ele ${ }^{15}$.

Assim, tanto há que se ter cuidado para não se inflar o grau de confiança da vítima/testemunha em momento subsequente à produção do feito, quanto é mais do que conveniente que se tenha também cautela à hora de valorar o grau de confiança por ela oferecido. No caso de Janet, ao mesmo tempo em que se atribuiu valor excessivo à confiança por ela relatada, foram deixadas de lado, à hora da valoração, importantes variáveis capazes de contaminar a sua memória. O fator estresse, o efeito da raça diferente, o efeito do foco na arma são apenas algumas das variáveis que no caso concreto foram desprezadas à hora de atribuir valor probatório ao reconhecimento realizado pela vítima.

14 O estupro de Janet Burke foi conteúdo do episódio seis da série "O DNA da Justiça”, que apresenta casos reais nos quais a atuação do Innocence Project Estados Unidos assegurou revisões criminais.

15 "O DNA de Justiça”, ep. 6, Netflix. 
Pelo que foi exposto, fica evidente a importância da realização de reconhecimento que observe as condições de (a) um alinhamento justo, essas, por seu turno, combinadas (b) ao oferecimento de instruções adequadas, capazes de prevenir eventual efeito compromisso que a vítima/testemunha seja capaz de sentir, correlacionando a continuidade da investigação ao apontamento de alguém. Além disso, também vimos o quão releva (c) eliminar o oferecimento de feedbacks à vítima/ testemunha, pois a flexibilidade da memória ocasiona a maleabilidade do grau de confiança.

A observância da reunião destes conselhos representa condição necessária e não suficiente para que se confira qualquer valor probatório, reduzido que seja, ao reconhecimento efetuado - seja ele presencial ou fotográfico: é condição necessária porque ausentes não se garante mínima confiabilidade ao resultado (dado que o próprio sistema de justiça estará contribuindo a falsos positivos), é condição insuficiente porque ainda quando todos as recomendações sejam seguidas, como a memória humana é falível, sempre se imporá a necessidade de que aquele reconhecimento seja corroborado por outros elementos probatórios extraídos de fontes independentes.

\section{ReConheCimento fotográfico, uma ALternativa A SER LEVADA A SÉRIO}

O uso de fotografias no reconhecimento de pessoas recebe constantes críticas no Brasil e no mundo. Uma pesquisa feita na Inglaterra perguntou a 406 pessoas que a qualquer momento poderiam ser selecionadas para compor o Júri qual método de reconhecimento tinham como mais confiável: $82 \%$ dos participantes responderam que o reconhecimento presencial era a alternativa mais confiável (Price et al, 2019). Some-se a ela, uma análise das legislações relativas a reconhecimento de cinquenta e quatro países demonstrou que, embora a maioria não especifique a preferência por um método de reconhecimento, quando o fazem, em geral, optam pelo reconhecimento presencial (Fitzgerald; Rubínová; Juncu, 2020). Estes resultados, todavia, não servem a concluir que o método presencial seja necessariamente melhor: em geral, membros do júri possuem pouco conhecimento sobre psicologia do testemunho (Desmarais; Don 
Read, 2011) e a maior parte das legislações do mundo sobre reconhecimento de pessoas não acompanha as recomendações científicas para a realização do procedimento (Fitzgerald; Rubínová; Juncu, 2020). Assim, para concluir se o procedimento presencial é espistemicamente melhor, é preciso verificar os resultados de pesquisas empíricas.

Quanto às objeções levantadas no contexto brasileiro, os casos reais mencionados neste artigo ilustram as notáveis irregularidades que circundam o uso de fotografias para se viabilizar a identificação do autor do delito. O envio de fotografias às vítimas/testemunhas via whatsapp, a exibição de fotografias despadronizadas de redes sociais, o álbum de suspeitos tornam merecidas as críticas ao reconhecimento fotográfico. Dois tipos de razões emprestam justificado fundamento às críticas ao aproveitamento de tais reconhecimentos: do ponto de vista epistêmico, não conduzem à verdade; do ponto de vista político-garantista, debilitam as garantias processuais penais do investigado/acusado, fazendo com que, desde o princípio da investigação sejam tomados como se culpados fossem, o que dificulta sobremaneira o exercício do direito de defesa no curso do processo, ao mesmo tempo em que facilita injustas condenações como seu desfecho. Enquanto o mero apontamento de alguém em tão deploráveis condições procedimentais seja considerado bastante para a sua qualificação como suspeito, é fato que a presunção de inocência não está a desempenhar limite ao abuso estatal como deveria.

Mas é precisamente porque nos preocupamos com o efetivo alcance dos direitos dos cidadãos quando investigados/processados que esclarecemos que a defesa do reconhecimento fotográfico não implica naturalização de ilegalidades cometidas na investigação. A modalidade fotográfica será oferecida aqui como alternativa que pode ser desenvolvida a oferecer resultados epistemicamente confiáveis, mas que, sem dúvidas, devem ter sua produção protocolizada e regulada institucionalmente. Fechada a porta para as arbitrariedades cometidas em sede de produção do reconhecimento de pessoas (HC 598.886/SC, relatoria Min. Rogerio Schietti), não se está agora a deixar janela aberta para estas mesmas arbitrariedades a partir da defesa ingênua de um desregrado reconhecimento por fotografia. Definitivamente, este não é o caso.

Assim, nesta seção apresentaremos argumentos a favor do método de reconhecimento fotográfico aliado à técnica de alinhamento justo. 
Serão expostas evidências advindas de pesquisas científicas empíricas as quais demonstram que o reconhecimento fotográfico é um método tão eficaz quanto o reconhecimento presencial. A continuação, argumentaremos no sentido de que o reconhecimento fotográfico consiste em método com maior viabilidade para o alinhamento justo, se comparado ao reconhecimento presencial. Por fim, abordaremos alguns desafios à efetiva implementação de um reconhecimento fotográfico justo no Brasil.

Como é de conhecimento dos que se interessam pela psicologia do testemunho, são inúmeras as variáveis que podem influenciar o reconhecimento. Sendo assim, pesquisadores têm feito uso de experimentos científicos, pois permitem controlar variáveis, isolando-as e com isso assegurando a validade de cada achado. Uma pesquisa pode, por exemplo, expor 100 participantes à mesma cena de crime e, após decorrido o mesmo o período de tempo de uma semana para todos os integrantes, testá-los organizados em distintos grupos: a uma metade expõe-se a foto do suspeito; à outra o suspeito é apresentado no modo presencial. Não se pode perder de vista a vantagem de que, no experimento, a identidade do autor do delito é previamente conhecida pelos pesquisadores, sendo possível verificar se a vítima/testemunha exposta a um suspeito culpado foi capaz de reconhecê-lo (reconhecimento correto), bem como se quando apresentada a um suspeito inocente conseguiu deixar de apontar algum deles (rejeição correta). A preferência pelo reconhecimento presencial depende da verificação de achados empíricos que demonstrem que o reconhecimento presencial efetivamente promove melhores resultados quando comparado ao reconhecimento fotográfico, isto é, que o reconhecimento presencial apresenta melhores taxas de reconhecimento e rejeição corretos de forma replicável por diferentes estudos.

Não é o caso, pois os achados empíricos não demonstram, de forma consistente, que o reconhecimento presencial sempre produz melhores resultados quando seus resultados são comparados aos do reconhecimento fotográfico. No experimento de Egan et al. (1977), 98\% dos participantes conseguiram reconhecer corretamente o suspeito quando presencialmente exibido, comparados aos $85 \%$ na exibição por foto. No entanto, no experimento de Kerstholt; Koster; Van Amelsvoort (2004), as taxas de reconhecimento correto foram de $69 \%$ para o método presencial em face dos $75 \%$ para a modalidade fotográfica. Ainda cabe 
asseverar que, neste experimento, as taxas de rejeição correta foram de $43 \%$ para o reconhecimento presencial, bastante inferior aos $71 \%$ apresentados pelo reconhecimento fotográfico. Uma revisão detalhada das pesquisas comparativas - isto é, que comparam reconhecimento presencial e fotográfico - não demonstra uma vantagem consistente de um método sobre outro: em alguns casos o reconhecimento presencial apresenta vantagens, noutros o reconhecido fotográfico, o que autoriza a conclusão de que ambos os métodos levam a resultados similares (Fitzgerald; Price; Valentine, 2018).

Um dos argumentos que frequentemente se apresenta a favor do reconhecimento presencial é que ele permite observar rostos por diferentes ângulos (Rubínová et al, 2020). Como um caminho intermediário projetado para superar a limitação da fotografia foi desenvolvido método de exibição da rosto por vídeo, em formato semelhante ao da fotografia de um documento, apresentando busto, rosto, por diversos ângulos, de modo a possibilitar a observação do rosto com maior profundidade e detalhes (Fitzgerald; Rubínová; Juncu, 2020; Rubínová et al., 2020). A despeito da direção a qual o senso comum apontaria, outra vez, inexistem vantagens substanciais de um método sobre o outro (Fitzgerald; Price; Valentine, 2018). As taxas de reconhecimento correto no experimento de Rubínová et al.(2020) foram de 31\% em um alinhamento no método presencial, e $29 \%$ em um método de vídeo; enquanto as taxas de rejeição correta foram de $66 \%$ no método presencial e $63 \%$ no método de vídeo.

Ademais, ainda entre os argumentos favoráveis ao reconhecimento presencial está o fato de que ele permitiria a observação de todo o corpo do suspeito, enquanto vídeo e foto limitar-se-iam ao busto das pessoas apresentadas no alinhamento. Sobre isso, há pelo menos duas considerações a serem feitas: em primeiro lugar, ainda que o corpo de uma pessoa possa auxiliar no reconhecimento, as maiores informações sobre a identidade de alguém estão presentes em seu rosto (Bruce; Young, 2012). O rosto de uma pessoa carrega diversas informações como idade, gênero, e até mesmo inferência de classe econômica, além de detalhes que tornam a imagem de um rosto única, mas são difíceis de descrever, como o formato dos olhos e a espessura dos lábios (Bruce; Young, 2012; Fiske; Taylor, 2013). O resultado da pesquisa realizada por Rubínová e seus colaboradores (2020) confirmam a considerável eficácia do 
reconhecimento fotográfico pois o reconhecimento correto da exibição do suspeito presencialmente e de corpo inteiro girou em $38 \%$, contra os $45 \%$ de acerto no reconhecimento pela modalidade fotográfica. Em segundo lugar, a descrição oferecida pela vítima/testemunha antes que se realize o reconhecimento servirá a registrar as características que, em sendo percebidas por ela, sejam relevantes; inclusive para excluir, em alguns casos, pessoas que apresentem características manifestamente incompatíveis com o que foi descrito previamente pela vítima/testemunha. A presença de suspeitos com estatura manifestamente discrepante à estatura descrita pela vítima/testemunha não se justifica, dado que a altura é característica inalterável na fase adulta.

O fato de que o reconhecimento presencial não apresenta resultados efetivamente melhores do que o reconhecimento fotográfico também chama atenção dos pesquisadores. Uma explicação plausível é que as condições de estresse e curta duração do evento dificultam o registro de características de um rosto que nunca vimos antes. É diferente recordar um rosto já visto a recordar um rosto desconhecido (Rubínová et al., 2020); daí, inclusive, a importância de se compreender o deletério efeito da repetibilidade do reconhecimento.

Além da paridade de resultados dos reconhecimentos nas modalidades presencial e fotográfico, cabe considerar o estresse que o momento do reconhecimento pode causar seja na vítima/testemunha, seja no suspeito. Na pesquisa de Brace et al. (2009), por exemplo, 70\% das testemunhas julgaram que o reconhecimento presencial gerou mais estresse que o reconhecimento via vídeo. Já a pesquisa de Dent; Stephenson (1979) comparou respostas de crianças para alinhamentos presenciais e fotográficos, verificando que além da ausência de vantagens substanciais do reconhecimento presencial quando comparado à modalidade fotográfica, o nível de ansiedade das crianças foi maior neste método. Nas palavras dos autores, "a maioria das crianças expostas ao alinhamento presencial demonstrou nervosismo, vergonha ou medo. Duas crianças demonstraram-se tão receosas a ponto de não conseguirem terminar a tarefa" ${ }^{16}$.

Finalmente, ainda importa considerar a ansiedade do suspeito. Inocente ou culpado, é plausível que demonstre ansiedade. O suspeito

16 Dent; Stephenson, 1979, p. 198 (tradução livre). 
culpado pode se mostrar ansioso porque sabendo que cometeu um crime, é consciente do risco de que venha a ser reconhecido e que, a consequência disso, venha a ser condenado. Quanto ao suspeito inocente, seu estado de ansiedade é igualmente plausível, dado que, uma vez seja erroneamente reconhecido acabará pagando por um crime que não cometeu. Finalmente, ainda no que concerne ao fator ansiedade, também é previsível que em um alinhamento presencial, os componentes inocentes (fillers) possam apresentar mais calma, uma vez que a sua seleção não representará maiores consequências o que, por sua vez, pode acabar produzindo destaque do suspeito - seja ele culpado ou inocente. Em um estudo realizado por Fabian, Stadler e Weltzels (1996) participantes inocentes foram exibidos como se fossem suspeitos em um alinhamento presencial. O experimento consistia em lhes apresentar a pessoas que não presenciaram qualquer delito, mas que deveriam identificar quem mais lhes aparentasse ser o culpado. O desfecho foi que estes suspeitos - inocentes porém ansiosos - foram de fato os escolhidos. A razão oferecida pelos participantes foi a aparência de destacada ansiedade e insegurança quando comparados aos demais. Estudos mais recentes (Flowe; Humphries, 2011, Flowe, Klatt; Colloff, 2014 e Weigold; Wentura, 2004) confirmam a correlação entre mostrar-se ansioso e parecer culpado aos olhos dos que selecionam o suspeito.

Finalmente, cabe o reconhecimento presencial também apresenta dificuldades de ordem prática. Uma pesquisa com mais de 18.000 casos reais na Inglaterra verificou que $52 \%$ dos procedimentos de reconhecimento presencial não foram realizados devido ao não comparecimento da testemunha/vítima, do suspeito, ou em razão da dificuldade de se encontrar fillers para compor o alinhamento (Pike; Brace; Kyan, 2002).

Não há razões para se esperar por um cenário mais otimista para o reconhecimento presencial com alinhamento justo em terras brasileiras. Como assegurar que em cada delegacia de polícia haverá pessoas semelhantes ao suspeito a disposição da realização de reconhecimentos? É simplesmente irreal supor que o desenho institucional da etapa investigatória possa depender da sorte de se ter disponíveis pessoas com as mesmas características físicas que a vítima/testemunha elencou como sendo as ostentadas pelo suspeito à espera da realização do reconhecimento, delegacias afora. E ainda que se pudesse pensar numa espécie de banco 
de dados de "fillers em potencial" para a composição de alinhamentos justos presenciais, sempre haveria o desafio de se lograr reunir cinco outras pessoas; cinco fontes de outros compromissos a partir de agendas; cinco vidas diferentes para a realização de um único reconhecimento. Todo o cotidiano de uma unidade policial giraria em torno de se montar reconhecimentos presenciais, como se não existissem outros elementos probatórios que lhes devesse importar.

O reconhecimento por foto (ou vídeo) não apresenta estas dificuldades práticas, pois apenas a presença da vítima/testemunha seria necessária para a sua realização. Para tanto, seria possível refletir sobre a criação de bancos de fotos de não suspeitos; de imagens de pessoas que pudessem ser apresentadas como fillers pois sabidamente inocentes da prática daquele delito em questão (por exemplo, pessoas que vivam em outras regiões, países, ou mesmo, imagens geradas a partir de programas que elaboram versões semelhantes ao próprio suspeito). Em procedimentos como estes, caberia ao responsável pelo reconhecimento tomar foto do suspeito (padronizada como todas as fotos pertencentes ao banco de dados) para então, com auxílio de software, pudesse buscar e selecionar não suspeitos similares para a composição de um alinhamento justo, sem destaques. Evidente que a criação de um sistema como este teria custos iniciais importantes, mas a séria comparação entre seus resultados com os resultados gerados por práticas como o show-up e o odioso álbum de suspeitos serviria a fortalecer não apenas sua conveniência, senão que a sua urgência.

O que gostaríamos de enfatizar é a imprescindibilidade de um alinhamento justo, de instruções adequadas e de ausência de feedbacks. São condições mínimas para se conferir contornos efetivos à presunção de inocência de todo e qualquer cidadão diante do risco de ser injustamente condenado. Se o alinhamento justo é mais fácil em reconhecimentos fotográficos, e se reconhecimentos presenciais não oferecem resultados consistentemente mais acurados aos reconhecimentos fotográficos, não estaríamos errando ao nos aferrarmos, a ferro e fogo, à defesa do reconhecimento presencial? Quando as evidências científicas apontam numa direção, a manutenção dos mesmos pontos de vista não nos tornaria equivalentes aos juízes que decidem por convicção íntima? Nosso entendimento é de que sim. 


\section{Conclusão}

Há, todavia, muito o que se debater sobre como realizar o reconhecimento fotográfico. Por ora, nossa pretensão foi de reduzir a dissonância cognitiva (Ritter, 2019) que o assunto envolve; a rejeição que práticas odiosas como a utilização de fotografias despadronizadas, sem o mínimo controle sobre sua proveniência, modo de exibição e quanto ao tempo pelo qual estará sob o domínio estatal é devida, mas o reconhecimento fotográfico não se confunde necessariamente com isso. Para tanto, o percurso aqui realizado passou por uma revisão da literatura oferecida pela psicologia do testemunho que contemplou pesquisas e experimentos cujos resultados servem a demonstrar a viabilidade do reconhecimento fotográfico. Isso porque, como foi trazido aqui, a despeito de uma atitude inicialmente cética e desconfiada (daí a dissonância), não há substanciais vantagens epistêmicas na adoção do reconhecimento presencial em detrimento do reconhecimento fotográfico. Não se justifica, portanto, toda a rejeição atribuída ao uso de fotografias.

Tendo isso em vista, nosso objetivo foi de singelamente contribuir a preparar o terreno para as reflexões absolutamente necessárias à construção de protocolos, bem como de ajustes legislativos que reconhecimentos epistemicamente confiáveis merecem de nós. Falar sobre reconhecimento fotográfico não é avalizar manifestas irregularidades, mas preencher de regras e protocolos lugares onde, nos dias de hoje, as arbitrariedades comodamente ainda imperam e contribuem às tormentosas condenações de inocentes.

\section{REFERÊNCIAS BIBLIOGRÁFICAS}

BADARÓ, Caio. A prova testemunhal no Processo Penal brasileiro: uma análise a partir da epistemologia e da psicologia do testemunho. Revista Brasileira de Ciências Criminais, ano 27, v. 156, 2019.

BADARÓ, Gustavo Henrique. Processo penal. São Paulo: Revista dos Tribunais, 4 ed. 2016.

BADARÓ, Gustavo Henrique. Epistemologia judiciária e prova penal. São Paulo: Revista dos Tribunais, 2019. 
BBC. Police offer virtual ID parades. 2003. http://news.bbc.co.uk/1/hi/techno$\operatorname{logy} / 2850803 . s t m$

BRACE, Nicola A. et al. Eye-Witness Identification Procedures and Stress: A Comparison of Live and Video Identification Parades. International Journal of Police Science \& Management, [s. l.], v. 11, n. 2, p. 183-192, 2009. https://doi. org/10.1350/ijps.2009.11.2.122

BRASIL. Supremo Tribunal de Justiça. Agravo em Recurso especial n. 175.175-AM. Agravante: Jardel Seixas Ribeiro e Paulo Silas Santos Maia. Relator: Ministro Rogério Schietti. Amazonas, 15 de Dezembro de 2017. Disponível em: https://stj.jusbrasil. com.br/jurisprudencia/861298645/agravo-regimental-no-agravo-em-recurso-especial-agrg-no-aresp-1175175-am-2017-0248721-6/inteiro=-teor861298655-?refserp Acesso em: 31 de outubro de 2020.

BRASIL. Supremo Tribunal de Justiça. Habeas Corpus n. 598.886-SC. Paciente: Vanio da Silva Gazola e Igor Tartari Felacio. Relator: Ministro Ministro Rogério Schietti. Santa Catarina, 27 de outubro de 2020. Disponível em: https://www.stj.jus.br/ sites/portalp/SiteAssets/documentos/noticias/27102020\%20HC598886-SC.pdf . Acesso em: 31 de outubro de 2020.

BRUCE, Vicki; YOUNG, Andrew W. Face perception. [S. l.]: Psychology Press, 2012.

CECCONELLO, William Weber; AVILA, Gustavo Noronha; STEIN, Lilian Milnitsky. A (ir)repetibilidade da prova penal dependente da memória: uma discussão com base na psicologia do testemunho. Revista Brasileira de Políticas Públicas, [s. l.], v. 8, n. 2, p. 1057-1073, 2018. https://doi.org/10.5102/rbpp.v8i2.5312

CECCONELLO, William Weber; FITZGERALD, Ryan J; STEIN, Lilian Milnitsky. Efeitos do alinhamento justo e similaridade de rostos no reconhecimento de pessoas. Psico-USF, [s. l.],

CECCONELLO, William Weber; STEIN, Lilian Milnitsky. Prevenindo injustiças: como a psicologia do testemunho pode ajudar a compreender e prevenir o falso reconhecimento de suspeitos. Avances en Psicologia Latinoamericana, [s. l.], v. 38, n. 1, p. 172-188, 2020. https://doi.org/10.12804/revistas.urosario.edu.co/ apl/a.6471

CLARK, S E. Costs and Benefits of Eyewitness Identification Reform: Psychological Science and Public Policy. Perspectives on Psychological Science, [s. l.], v. 7, n. 3, p. 238-259, 2012. Disponível em: https://doi.org/10.1177/1745691612439584 
DENT, Helen R.; STEPHENSON, Geoffrey M. Identification Evidence: Experimental Investigations of Factors Affecting the Reliability of Juvenile and Adult Witnesses. Psychology, Law and Legal Processes, [s. l.], p. 195-206, 1979. https:// doi.org/10.1007/978-1-349-04248-7_13

DESMARAIS, Sarah L.; DON READ, J. After 30 years, what do we know about what jurors know? A meta-analytic review of lay knowledge regarding eyewitness factors. Law and Human Behavior, [s. l.], v. 35, n. 3, p. 200-210, 2011. https:// doi.org/10.1007/s10979-010-9232-6

EGAN, David et al. Photographs vs. Live Models. [s. l.], v. 1, n. 2, p. 199-206, 1977.

FABIAN, T.; STADLER, M; WETZELS, P. The "authenticity error" in real lineup procedure. Effects of suspect-status and corresponding psychological dissimilarities between target person and distractors: An experimental study. In: DAVIES, G. et al. (org.). Psychology, law, and criminal justice: International developments in research and practice. Berlin: Walter de Gruyter, 1996. p. 29-38.

FINDLEY, Keith; SCOTT, Michael. The Multiple Dimensions of Tunnel Vision In Criminal Cases. Wisconsin Law Review, n. 1023, 2006. pp. 291-397.

FISKE, Susan T; TAYLOR, Shelley E. Social cognition: From brains to culture. [S. l.]: Sage, 2013.

FITZGERALD, Ryan J.; PRICE, Heather L.; VALENTINE, Tim. Eyewitness identification: Live, photo, and video lineups. Psychology, Public Policy, and Law, [s. l.], v. 24, n. 3, p. 307-325, 2018. https://doi.org/10.1037/law0000164

FITZGERALD, Ryan J; RUBÍNOVÁ, Eva; JUNCU, Stefana. Eyewitness Identification Around the World. In: SMITH, A.M; TOGLIA, M. P; LAMPINEM, J.M (org.). Methods, measures, and theories in eyewitness identification tasks. [S. l.]: Taylor and Francis, 2020.

FLOWE, Heather D.; HUMPHRIES, Joyce E. An examination of criminal face bias in a random sample of police lineups. Applied Cognitive Psychology, [s. l.], v. 25, n. 2, p. 265-273, 2011. https://doi.org/10.1002/acp.1673

FLOWE, Heather D.; KLATT, Thimna; COLLOFF, Melissa F. Selecting fillers on emotional appearance improves lineup identification accuracy. Law and Human Behavior, [s. l.], v. 38, n. 6, p. 509-519, 2014. https://doi.org/10.1037/lhb0000101 
GIACOMOLLI, Nereu; di Gesu, Cristina. As falsas memórias na reconstrução dos fatos pelas testemunhas no processo penal. Anais do XVII Congresso Nacional do CONPEDI, 2008.

KERSTHOLT, José H; KOSTER, Erwin R; VAN AMELSVOORT, Adri G. Eyewitnesses: A comparison of live, video, and photo line-ups. Journal of Police and Criminal Psychology, [s. l.], v. 19, n. 2, p. 15-22, 2004. Disponível em: https:// doi.org/10.1007/BF02813869

LOPES Jr., Aury. Direito Processual Penal. 17 ed. São Paulo: Saraiva, 2020.

LOPES, Mariângela Lopes. O reconhecimento como meio de prova: necessidade de reformulação do direito brasileiro. Tese de doutorado, USP. Acesso em 6 de fevereiro de 2021 por: https://www.teses.usp.br/teses/disponiveis/2/2137/ tde-10092012-160242/publico/TESE_DOUTORADO_FINAL_MARIANGELA_TOME_LOPES.pdf

MACHADO, Leonardo.M.; MORETZSOHN, Fernanda.; BURIN, Patrícia. O reconhecimento de pessoas e o papel do delegado na condução das investigações. Conjur, 2020. Disponível em: https://www.conjur.com.br/2020-dez-15/academia-policia-reconhecimento-pessoas-papel-delegado-conducao-investigacoes . Acesso 15 de dezembro de 2020.

MANSOUR, Jamal K. et al. Impact of disguise on identification decisions and confidence with simultaneous and sequential lineups. [S. l.: s. n.], 2012. ISSN 01477307.v. 36 Disponível em: https://doi.org/10.1037/h0093937

MATIDA, Janaina; HERDY, Rachel. As inferências probatórias: compromissos epistêmicos, normativos e interpretativos. In Cunha, J. R. (Org.). Epistemologias Críticas do Direito. Rio de Janeiro: Lumen Juris, 2016.

MATIDA, Janaina. "Standards de prova: a modéstia necessária a juízes e o abandono da prova por convicção”. In Caldas, D.F.; Andrade, G.L.; Rios, L.C. (Org). Arquivos da Resistência: ensaios e anais do VII Seminário Nacional do IBADPP 2018, Florianópolis: Tirant lo Blanch, 2019.

MATIDA, Janaina et al. A prova de reconhecimento de pessoas não será mais a mesma. [S. l.]: Conjur, 2020. Disponível em: https://www.conjur.com.br/2020-out-30/ limite-penal-prova-reconhecimento-pessoas-nao-mesma. Acesso 15 dse dezembro de 2020. 
MATIDA, Janaina. O reconhecimento de pessoas não pode ser porta aberta à seletividade penal. Conjur, 2020. Disponível em: https://www.conjur.com.br/2020-set-18/ limite-penal-reconhecimento-pessoas-nao-porta-aberta-seletividade-penal?pagina=2. Acesso 15 dse dezembro de 2020 .

MATIDA, Janaina; NARDELLI, Marcella Marcella. Álbum de suspeitos: uma vez suspeito, para sempre suspeito? Conjur, 2020. Disponível em: https://www.conjur. com.br/2020-dez-18/limite-penal-album-suspeitos-vez-suspeito-sempre-suspeito. Acesso 15 de dezembro de 2020.

MATIDA, Janaina; NARDELLI, Marcella; HERDY, Rachel. A prova precisa passar por uma filtragem epistêmica. Conjur, 2020. Disponível em: https://www.conjur. com.br/2020-mar-13/limite-penal-prova-penal-passar-filtragem-epistemica. Acesso 15 de dezembro de 2020.

MORAIS DA ROSA, Alexandre. Guia do Processo Penal conforme a Teoria dos Jogos. 6ed. Florianópolis: EMais Editora, 2020.

NARDELLI, Marcella Mascarenhas. A prova no Tribunal do Júri: uma abordagem racionalista. Rio de Janeiro: Lumen Juris, 2019.

PIKE, Graham; BRACE, Nicola; KYNAN, Sally. Visual Identification of Suspects: Procedures and Practice. Home Office Briefing Note 2/02, [s. l.], n. Id, p. 1-6, 2002. Disponível em: https://s3.amazonaws.com/academia.edu.documents/40203084/ THE_VISUAL_IDENTIFICATION_OF_SUSPECTS_PR20151120-29245-1x7bou8. pdf?response-content-disposition=inline\%3B filename\%3DThe_Visual_Identification_of_Suspects_Pr.pdf\&X-Amz-Algorithm=AWS4-HMAC-SHA256\&X-A

POLICE EXECUTION RESEARCH FORUM. A National Survey of Eyewitness Identification Procedures in Law Enforcement Agencies. [S. l.: s. n.], 2013. Disponível em: http://reid.com/pdfs/NIJEyewitnessReport.pdf

PRADO, Geraldo. Prova penal e sistema de controles epistêmicos: a quebra da cadeia de custódia das provas obtidas por métodos ocultos. São Paulo: Marcial Pons, 2014.

PRADO, Geraldo. A cadeia de custódia da prova no processo penal. São Paulo: Marcial Pons, 2019.

PRICE, Heather L. et al. Evidence for the Belief in Live Lineup Superiority. Journal of Police and Criminal Psychology, [s. l.], v. 34, n. 3, p. 263-269, 2019. Disponível em: https://doi.org/10.1007/s11896-018-9305-x 
RAMOS, Vitor de Paula. Prova testemunhal. Do subjetivismo ao Objetivismo. Do Isolamento Científico ao Diálogo com a Psicologia e a Epistemologia. São Paulo: Revista dos Tribunais, 2018.

RITTER, Ruiz. Imparcialidade no processo penal: reflexões a partir da teoria da dissonância cognitiva. 2a ed. São Paulo: Tirant lo blanch, 2019.

RUBÍNOVÁ, Eva et al. Live Presentation for Eyewitness Identification is Not Superior to Photo or Video Presentation. Journal of Applied Research in Memory and Cognition, Amsterdam, p. 1-10, 2020. https://doi.org/10.1016/j.jarmac.2020.08.009

STEBLAY, Nancy K. Lineup instructions. In: B. L. Cutler (Ed.), Reform of eyewitness identification procedures, p. 65-86. Washington: American Psychological Association2013. https://doi.org/10.1037/14094-004

STEBLAY, Nancy K.; DYSART, Jennifer E. Repeated Eyewitness Identification Procedures with the Same Suspect. Journal of Applied Research in Memory and Cognition, Amsterdam. v. 5, n. 3, p. 284-289, 2016. https://doi.org/10.1016/j. jarmac.2016.06.010

STEBLAY, Nancy K; WELLS, Gary L; DOUGLASS, Amy Bradfield. The eyewitness post identification feedback effect 15 years later: Theoretical and policy implications. Psychology, Public Policy, and Law. Washington, v.20, n.1 American Psychological Association, 2014.

STEIN, Lilian. M.; ÁVILA, Gustavo. N. Avanços científicos em Psicologia do Testemunho aplicados ao reconhecimento pessoal e aos depoimentos forenses. Brasilia: Secretaria de Assuntos Legislativos, Ministério da Justiça (Série Pensando Direito, No. 59)., 2015. Disponível em: http://pensando.mj.gov.br/wp-content/ uploads/2016/02/PoD_59_Lilian_web-1.pdf Acesso em 05 de novembro de 2020

TECHNICAL WORKING GROUP ON EYEWITNESS EVIDENCE. Eyewitness Evidence: A Guide to for law enforcement. Washington, D.C: US Department of Justice, 1999.

VIEIRA, Antonio. Riscos epistêmicos no reconhecimento de pessoas: o que aprender com a reforma do Código Processual Penal Uruguaio. In: Coutinho, J. N. M; Postigo, L. G; Silveira, M. A. N: Reflexiones brasileñas sobre la reforma procesal penal en Uruguay: hacia la justicia acusatoria en Brasil. Curitiba: Observatório da Mentalidade Inquisitória, 2019. 
WEIGOLD, Arne; WENTURA, Dirk. Who's the one in trouble? Experimental evidence for a "psychic state" bias in lineups. European Journal of Social Psychology, Oxford, v. 34, n. 2, p. 121-133, 2004. https://doi.org/10.1002/ejsp.193

WELLS, Gary L et al. Policy and procedure recommendations for the collection and preservation of eyewitness identification evidence. Law and Human Behavior, Nova York, v. 44, n. 1, p. 3, 2020. https://doi.org/10.1037/lhb0000359

WELLS, Gary L.; OLSON, Elizabeth A. Eyewitness Testimony. Annual Review of Psychology, Palo Alto v. 54, n. 1, p. 277-295, 2003. https://doi.org/10.1146/ annurev.psych.54.101601.145028

WELLS, Gary L.; SMALARZ, Laura; SMITH, Andrew M. ROC analysis of lineups does not measure underlying discriminability and has limited value. Journal of Applied Research in Memory and Cognition, Amsterdam, v. 4, n. 4, p. 313-317, 2015. https://doi.org/10.1016/j.jarmac.2015.08.008

WIXTED, John T. et al. Models of lineup memory. Cognitive Psychology, Cambridge v. 105, n. July, p. 81-114, 2018. https://doi.org/10.1016/j.cogpsych.2018.06.001 


\section{Informações adicionais e declarações dos autores (integridade científica)}

Declaração de conflito de interesses (conflict of interest declaration): a/os autores confirmam que não há conflitos de interesse na realização das pesquisas expostas e na redação deste artigo.

Declaração de autoria e especificação das contribuições (declaration of authorship): todas e somente as pessoas que atendem os requisitos de autoria deste artigo estão listadas como autores; todos os coautores se responsabilizam integralmente por este trabalho em sua totalidade.

- Janaina Matida: projeto e esboço inicial (conceptualization), desenvolvimento da metodologia (methodology), coleta e análise de dados (data curation), levantamento bibliográfico (investigation), revisão bibliográfica (investigation), redação (writing - original draft), participação ativa nas discussões dos resultados (validation), revisão crítica com contribuições substanciais (writing - review and editing), aprovação da versão final.

- William Weber Cecconello: projeto e esboço inicial (conceptualization), desenvolvimento da metodologia (methodology), coleta e análise de dados (data curation), levantamento bibliográfico (investigation), revisão bibliográfica (investigation), redação (writing - original draft), participação ativa nas discussões dos resultados (validation), revisão crítica com contribuições substanciais (writing - review and editing), aprovação da versão final.

Declaração de ineditismo e originalidade (declaration of originality): a/os autores asseguram que o texto aqui publicado não foi divulgado anteriormente em outro meio e que futura republicação somente se realizará com a indicação expressa da referência desta publicação original; também atestam que não há plágio de terceiros ou autoplágio. 


\section{Dados do processo editorial}

(http://www.ibraspp.com.br/revista/index.php/RBDPP/about/editorialPolicies)

- Recebido em: 22/12/2020

- Controle preliminar e verificação de plágio: 04/01/2021

- Avaliação 1: 08/01/2021

- Avaliação 2: 18/01/2021

- Avaliação 3: 18/01/2021

- Avaliação 4: 18/01/2021

- Avaliação 5: 28/01/2021

- Decisão editorial preliminar: 02/02/2021

- Retorno rodada de correções: 22/02/2021

- Decisão editorial final: 22/02/2021
Equipe editorial envolvida

- Editor-chefe: 1 (VGV)

- Editora-associada: 1 (KK)

- Revisores: 5

\section{COMO CITAR ESTE ARTIGO:}

MATIDA, Janaina; CECCONELLO, William W. Reconhecimento fotográfico e presunção de inocência. Revista Brasileira de Direito Processual Penal, Porto Alegre, vol. 7, n. 1, p. 409-440, jan./abr. 2021. https://doi.org/10.22197/rbdpp.v7i1.506

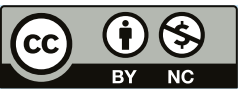

Esta obra está licenciada com uma Licença Creative Commons Atribuição-NãoComercial 4.0 Internacional. 